\title{
Evaluation of Dose Change by Using the Deformable Image Registration (DIR) on the Intensity Modulated Radiation Therapy (IMRT) with Glottis Cancer
}

\author{
Woo Chul Kim* ${ }^{\dagger}$, Chul Kee Min*, Suk Lee ${ }^{\dagger}$, Sang Hyoun $\mathrm{Choi}^{\S}$, Kwang Hwan Cho*, \\ Jae Hong Jung* ${ }^{*}$, Eun Seog Kim*, Seung-Gu Yeo*, Soo-II Kwon ${ }^{\dagger \uparrow}$, Kil-Dong Lee ${ }^{+\pi}$, \\ *Department of Radiation Oncology, Soonchunhyang University College of Medicine, Cheonan, \\ ${ }^{\dagger}$ Department of Medical Physics, Kyonggi University, Suwon, \\ ${ }^{\dagger}$ Department of Radiation Oncology, College of Medicine, Korea University, \\ ${ }^{\S}$ Research Center for Radiotherapy, Korea Institute of Radiological and Medical Science, \\ "Department of Biomedical Engineering and Research Institute of Biomedical Engineering, The Catholic \\ University, Seoul, "Department of Electrophysics, Kyonggi University, Suwon, Korea
}

\begin{abstract}
The purpose of this study is to evaluate the variation of the dose which is delivered to the patients with glottis cancer under IMRT (intensity modulated radiation therapy) by using the 3D registration with CBCT (cone beam CT) images and the DIR (deformable image registration) techniques. The CBCT images which were obtained at a one-week interval were reconstructed by using B-spline algorithm in DIR system, and doses were recalculated based on the newly obtained CBCT images. The dose distributions to the tumor and the critical organs were compared with reference. For the change of volume depending on weight at 3 to 5 weeks, there was increased of $1.38 \sim 2.04 \mathrm{~kg}$ on average. For the body surface depending on weight, there was decreased of $2.1 \mathrm{~mm}$. The dose with transmitted to the carotid since three weeks was increased compared be more than $8.76 \%$ planned, and the thyroid gland was decreased to $26.4 \%$. For the physical evaluation factors of the tumor, PITV, TCI, rDHI, $\mathrm{mDH}$, and $\mathrm{CN}$ were decreased to $4.32 \%, 5.78 \%, 44.54 \%, 12.32 \%$, and $7.11 \%$, respectively. Moreover, $D_{\max }, D_{\operatorname{mean}}, V_{67.50}$, and $D_{95}$ for PTV were increased or decreased to $2.99 \%, 1.52 \%, 5.78 \%$, and $11.94 \%$, respectively. Although there was no change of volume depending on weight, the change of body types occurred, and IMRT with the narrow composure margin sensitively responded to such a changing. For the glottis IMRT, the patient's weight changes should be observed and recorded to evaluate the actual dose distribution by using the DIR techniques, and more the adaptive treatment planning during the treatment course is needed to deliver the accurate dose to the patients.
\end{abstract}

Key Words: Glottic, Deformable image registration, CBCT, Adaptive radiation therapy

\section{서 론}

최근, 두경부암 환자에 대하여 체외 방사선 치료는 기존 의 전통적인 방법(2 Demensional, 2D)과 입체조형치료(3 dimensional conformal radiation therapy, 3D CRT) 뿐만 아니라, 세기조절 방사선치료(intensity modulated radiation therapy,

Received 14 August 2014, Revised 11 September 2014, Accepted 12 September 2014

Correspondence: Kil-Dong Lee (gdlee@kyonggi.ac.kr) Tel: 82-31-253-9621, Fax: 82-31-253-1165

(C) This is an Open-Access article distributed under the terms of the Creative Commons Attribution Non-Commercial License (http://creativecommons.org/licenses/by-nc/3.0) which permits unrestricted non-commercial use, distribution, and reproduction in any medium, provided the original work is properly cited.
IMRT)가 보편적으로 사용되고 있다. 성문암(glottis cancer) 에 대한 IMRT는 고전적인 방사선 치료 방법인 대항 2문 조사에 비해 성문의 계획용표적체적(planning target volume, PTV)에 종양포함(target coverage)을 이루면서 정상장기인 경동맥(carotid arteries)과 갑상선샘(thyroid gland)에 대한 불 필요한 선량을 줄일 수 있다는 장점이 있다. ${ }^{1)}$ 그러나, 일반 적으로 두경부암 환자에서는 방사선치료 기간 동안 체중감 소, 부종(edema) 등의 이유로 정상조직의 체적변형과 종양 의 이동 및 변화가 발생될 수 있고, 이로 인하여 선량분포 의 불일치성을 가져올 수 있음으로써 선량분포변화에 직접 적인 영향을 줄 수 있다. ${ }^{2-4)}$ Nishimura Y. 등)는 IMRT 치료 과정 중 이하선(parotid gland)의 체적이 $74 \%$ 감소하고 체표 
Woo Chul Kim, et al : Evaluation of Dose Change by Using the DIR on the IMRT with Glotiis Cancer

윤곽의 변화가 발생하여 선량분포에 영향을 미칠 수 있다 고 보고하였다. 또한, Schwartz 등은 두경부암 환자에서 적응형방사선치료의 전향적 연구를 수행함으로써 하나 또 는 두 개의 적응형치료계획(adaptive radiotherapy, ART)은 선량적인 측면과 임상적인 측면에서 이득을 제공한다고 보 고하였다.

치료 전 CBCT (cone beam computed tomography), MVCT (megavoltage computed tomography), 내장영상장치(on-board imager, OBI) 등과 같은 영상 유도 기술은 치료 전 종양의 위치, 크기 및 변형 등을 확인할 수 있고, 오차를 보정하는 데 이용된다. 이는 최초 계획한 치료의 정확성과 재현성을 높여줄 수 있고, 치료 과정에서 재 치료계획 즉, 적응형방 사선치료을 수행할 수 있다. 결과적으로 적응형방사선치료 는 치료기간 동안 발생할 수 있는 변화를 능동적으로 대처 함으로써, 최종적으로 치료 성적을 높일 수 있는 기회를 제 공한다. ${ }^{7-8)}$

본 연구의 목적은 IMRT를 적용한 성문암 환자에 대하여 CBCT영상과 변형영상 정합기법(deformable image registration, DIR)을 적용하여 치료 기간 동안 실제 환자에게 전달 되는 선량 변화를 평가하고자 하였다.

\section{재료 및 방법}

\section{1. 대상환자 및 방사선치료계획}

대상환자는 2011년 1월부터 2013년 5월까지 본원에서 IMRT를 적용하여 치료가 종료된 성문암 환자 중 병기가 T1-2N0M0이고 IMRT를 받은 5명을 선정하였다. 치료계획 을 위하여 촬영된 planning-kVCT영상은 16 채널 전산화 단 층 모의치료기(Brilliance CT Big Bore, Philips Medical System, Cleveland, OH, USA)를 사용하여 $120 \mathrm{kVp}, 50 \mathrm{~mA}$, $2 \mathrm{~mm}$ 두께로 영상을 획득하였다. 임상표적체적(clinical target volume, CTV)범위는 위로 상갑상연골돌출(superior thyroid notch)부터 아래로 윤상연골(cricoid cartilage) 하연까지 포함하였으며, 가성/진성 성대(false/true vocal cord), 앞/뒤 맞교차(anterior/posterior commissure), 피열연골(aryenoid cartilage), 성문하부(subglottis) 부분 등을 포함하였고, 경부 림프 절은 포함하지 않았다. PTV는 CTV 주변으로 $0.5 \mathrm{~cm}$ 마진 을 두어 설정하였다. 종양이 앞 맞교차 범위를 침범하지 않 은 경우, PTV는 피부표면으로부터 $0.5 \mathrm{~cm}$ 떨어지도록 조정 하였다. 주변 정상 장기는 경동맥, 갑상선, 척수의 윤곽을 그렸다. 경동맥은 위로 두개저부로부터 아래로 복장빗장관 절(sternoclavicular jonits) 위치까지 윤곽을 그렸다. 방사선치 료계획시스템(eclipse ${ }^{\circledR}, 8.9$ Platform, Varian Medical System, Palo Alto, CA, USA)을 이용하여 IMRT 치료계획을 수행하 였다. MLC (multi-leap collimator)는 HD-120 (Varian Medical Systems, Palo Alto, CA, USA)으로 구성되어 있으며, MLC 의 움직임 계산은 sliding window technique 방식을 사용하 였다. PTV에 대한 처방선량(prescription dose)은 총 $67.5 \mathrm{~Gy}$ 이고, $2.25 \mathrm{~Gy}$ 씩 30 회 분할하여 $\mathrm{PTV}$ 의 $95 \%$ 가 포함되도록 처방하였다. $6 \mathrm{MV}$ 광자선을 이용하였으며, 7에서 9개의 빔 을 사용하여 치료계획을 수립하였다.

\section{2. $\mathrm{CBCT}$ 영상획득과 변형영상정합(DIR)}

본 연구에서 모든 환자는 치료 중 $\mathrm{CBCT}$ 를 이용하여 $110 \mathrm{kVp}, 20 \mathrm{~mA}, 2 \mathrm{~mm}$ 두께로 방사선 치료 시작일부터 일 주일 간격으로 영상을 획득하였고, 각 환자마다 총 $5 \mathrm{set}$ 의 $\mathrm{CBCT}$ 영상을 획득하였다. $\mathrm{CBCT}$ 는 획득한 영상은 방사선치 료계획시스템과 변형영상정합시스템인 Velocity AI (ver. 2.7.0)로 전송하였다. 변형영상정합 시스템에서 미리 획득 한 $\mathrm{CBCT}$ 와 planning-kVCT는 강직영상정합(rigid image registration)이 선행되었으며, 빼-조직을 기반으로 영상간의 정 합을 수행하였다. B-spline 알고리즘을 이용하여 변형영상 정합을 수행하였고, 의사와 함께 경추 4 에서 6 번과 하악골 의 위치를 육안으로 영상비교를 하여 변형영상정합이 잘 수행되었는지 확인하였다. 최종적인 결과물로써 각각의 변 형영상정합 된 CT 영상과 모든 해부학적 구조(structures, $\mathrm{STC})$ 의 리샘플 된 정보(resampled data)를 획득하였다.

\section{3. 방사선량재계산}

변형영상정합 과정에서 각 환자로부터 획득한 resampledCT (r-CT)와 resampled-structure (r-STC) 정보를 방사선치료 계획시스템으로 전송하였다. 실험에 필요한 해부학적 구조 물들은 의사에 의해 다시 그려져 확인하였다. planning-kVCT 와 resampled-CT의 경동맥에서 CT number는 200 210 HU, PTV 위치의 경추 $4 \sim 6$ 번 추체 영역에서는 평균적으로 각 각 $224 \mathrm{HU}, 225 \mathrm{HU}$ 값으로 $\mathrm{CT}$ 영상간의 전자밀도 차이가 없음을 확인하였다. 동일한 조건에서 비교평가를 하기 위 하여 최초에 계획된 IMRT 치료계획(original plan, o-plan)을 동일한 조건하에 resampled-CT에 적용하여 역 선량계산 (inverse dose calculation)을 수행하였다. 모든 과정은 하나의 resampled-CT에 대하여 동일한 조건에서 총 5 회 반복 수행 되었다. Planning-kVCT 영상을 이용한 치료계획인 o-plan과 resampled-CT을 이용하여 재계산 된 치료계획은 PTV와 결 정장기에 대한 선량을 구하기 위하여 각 STC의 체적(volume) 
과 선량-체적간 히스토그람(dose volume histogram, DVH)을 이용하였다.

\section{4. 선량분석 평가 인자}

PTV에 대한 선량평가분석에 사용된 인자들은 체적 변화, 최대 선량 $\left(\mathrm{D}_{\max }\right)$, 평균 선량 $\left(\mathrm{D}_{\text {mean }}\right)$, 표적 포함도(dose coverage), 처방등선량표적체적(prescription isodose target volume conformal index, PITV), 표적선량지수(target coverage index, $\mathrm{TCI}$ ), 라디칼 선량 균질성 지수(radical dose homogeneity index, rDHI), 감속 균질성 지수(moderate homogeneity index, $\mathrm{mDHI}$ 그리고, $\mathrm{CN}$ (conformation number)을 이용하였다.

PITV는 계획한 선량에 대하여 전달된 선량의 비를 나타 내며 PITV $>1$ 은 계획보다 선량이 많이 전달된 것이고, $\mathrm{PITV}<1$ 은 계획보다 선량이 적게 전달된 것을 의미한다. $\mathrm{TCI}$ 는 PTV에 처방선량이 얼마나 전달되었는지 확인하는 지수로 $\mathrm{TCI}=1$ 일 때 가장 이상적인 치료계획을 의미한다. 타겟에 대하여 선량의 균일성(uniformity)을 평가하기 위하 여 $\mathrm{rDHI}$ 와 $\mathrm{mDHI}$ 가 사용되었다. M. Oliver 등')은 $\mathrm{rDHI}$, $\mathrm{mDHI}$ 를 다음과 같이 표현하였다.

$$
r D H I=\frac{D_{\min }}{D_{\max }}, m D H I=\frac{D_{\geq 95 \%}}{D_{\geq 5 \%}}
$$

여기서 $D_{\geq 95}$ 는 타겟 체적의 $95 \%$ 선량을 의미하며, $D_{\geq 5} \%$ 는 타겟 체적의 $5 \%$ 선량을 의미한다. $\mathrm{CN}$ 은 치료계획에서 정상조직을 보호하고 선량 표적 범위의 상대적인 측정을 설명하는 지수이다.

결정장기인 경동맥과 갑상선 샘에 대한 평가는 체적 변 화, $\mathrm{D}_{\max }, \mathrm{D}_{\text {mean, }}, \mathrm{V}_{30}, \mathrm{~V}_{40}$, 그리고, $\mathrm{V}_{50}$ 를 이용하였다.

\section{결과 및 고찰}

\section{1. 체중 변화}

두경부암 환자의 방사선 치료 시 체내 선량분포를 변화 시키는 요인은 체중 변화에 인한 체형의 변화, 종양 및 정 상조직의 변화, 환자 자세 등을 예로 들 수 있다. Fig. 1은 치료 기간 동안 환자의 체중변화를 보여주고 있다. 체중변 화는 방사선 치료가 시작한 후 1 주일 사이에 모든 환자가 평균 $0.56 \pm 0.22 \mathrm{~kg}$ 으로 증가 하였고, 2주에는 평균 $0.62 \pm$ $0.78 \mathrm{~kg}$ 으로 증가 또는 감소하였다. 이러한 현상은 방사선 치료 시작 이후, 2 주 동안은 체중의 변화로 인한 체형의 변 화가 거의 없었다는 것을 의미한다. 반면 3,4 그리고 5 주
부터는 각각 평균 $1.90 \pm 2.27 \mathrm{~kg}, 2.60 \pm 3.68 \mathrm{~kg}$ 그리고, $2.30 \pm 3.15 \mathrm{~kg}$ 으로 증가 또는 감소하였다. 3주 이후의 체중 변화는 $-1.20 \sim 8.00 \mathrm{~kg}$ 로 체형의 변화가 관측되었고, 이는 종전의 연구자들의 보고와 유사한 결과를 보였다. 보통 항 암 방사선 동시요법(concurrent chemo-radiotherapy, CCRT) 환자의 경우 체중 감소가 $7 \%$ 11\% 일어날 수 있다고 보고 된 바 있지만 ${ }^{10)}$ 본 연구에서 5 명의 환자들은 약물병합치료 대상이 아닌 오로지 방사선치료만 시행되었다. 약물병합치 료 대상이 아닌 경우에도 체중의 변화는 발생하였고 이로 인하여 해부학적인 변화로 인한 즉, 체내 선량분포가 변화 가 예측 되었다.

\section{2. 종양과 정상조직의 체적 변화}

Table 1에서는 치료 기간 동안 PTV 및 OARs의 체적변화 를 보여주고 있으며, PTV는 $-3.29 \sim 3.61 \mathrm{~cm}^{3}$, 경동맥은 $-0.62 \sim 0.21 \mathrm{~cm}^{3}$ 그리고, 갑상선 샘은 $-1.81 \sim 0.13 \mathrm{~cm}^{3}$ 의 변화를 보였다. Fig. 2에서는 특정 환자의 OARs 체적 외 체 형의 해부학적인 변화를 분석하기 위해 4 지점에서 체표면 까지의 거리를 비교하여 보여주고 있다. 각 planning-kVCT 영상과 일주일 간격으로 획득한 모든 resampled-CT영상에 서 임의의 단면영상(axial image)을 정하여 갑상연골(thyroid cartilage)의 앞쪽표면(anterior surface)과 측면표면(lateral surface) 부분의 피부까지의 거리, 경동맥의 앞쪽과 측면의 표 면과 피부 사이의 거리를 측정하였다. planning-kVCT와 비 교하였을 때 치료가 진행되는 동안 갑상연골의 앞쪽표면과

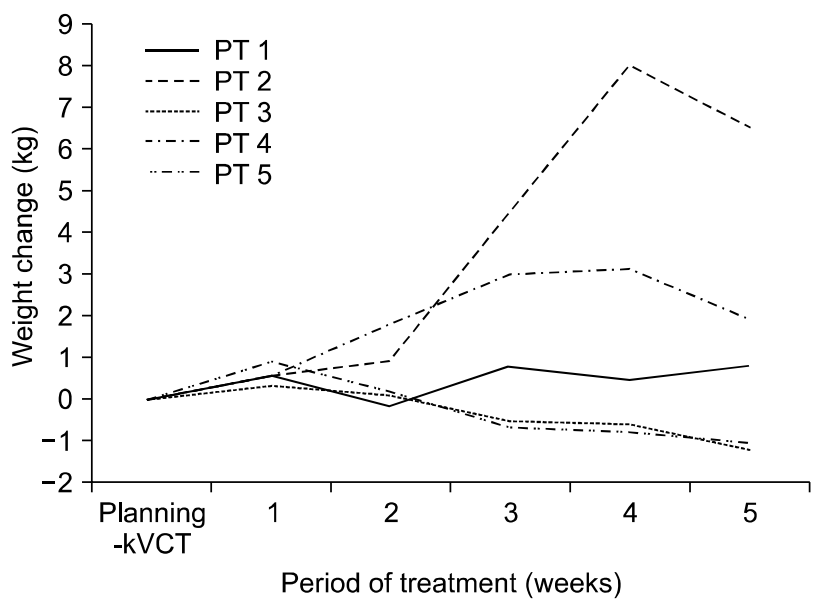

Fig. 1. The change of weight during the period of treatment. The difference of weight change for $1 \sim 5$ weeks after commencing the treatment based on the weight when the planningkVCT has been acquired for the treatment plan. 
Woo Chul Kim, et al : Evaluation of Dose Change by Using the DIR on the IMRT with Glotiis Cancer

Table 1. Average of volume change on PTV and OARs.

\begin{tabular}{cccc}
\hline Weekly & PTV \pm SD [cc] & Carotid A. \pm SD [cc] & Thyroid gland \pm SD [cc] \\
\hline Planning-kVCT & $71.63 \pm 24.19$ & $12.25 \pm 3.28$ & $14.18 \pm 4.97$ \\
1 week & $71.16 \pm 24.19$ & $12.10 \pm 3.42$ & $13.99 \pm 4.95$ \\
2 week & $70.85 \pm 24.04$ & $11.91 \pm 3.33$ & $13.70 \pm 4.35$ \\
3 week & $70.26 \pm 25.04$ & $11.88 \pm 3.27$ & $13.66 \pm 4.62$ \\
4 week & $71.69 \pm 22.69$ & $11.93 \pm 3.22$ & $13.43 \pm 4.43$ \\
5 week & $71.39 \pm 23.28$ & $11.91 \pm 3.28$ & $13.34 \pm 4.37$ \\
\hline \hline
\end{tabular}

Note: The volume of the PTV, carotid artery and thyroid gland on planning-kVCT images and the average of volume change on $\mathrm{CBCT}$ images acquired at 1 week intervals during the course of treatment.
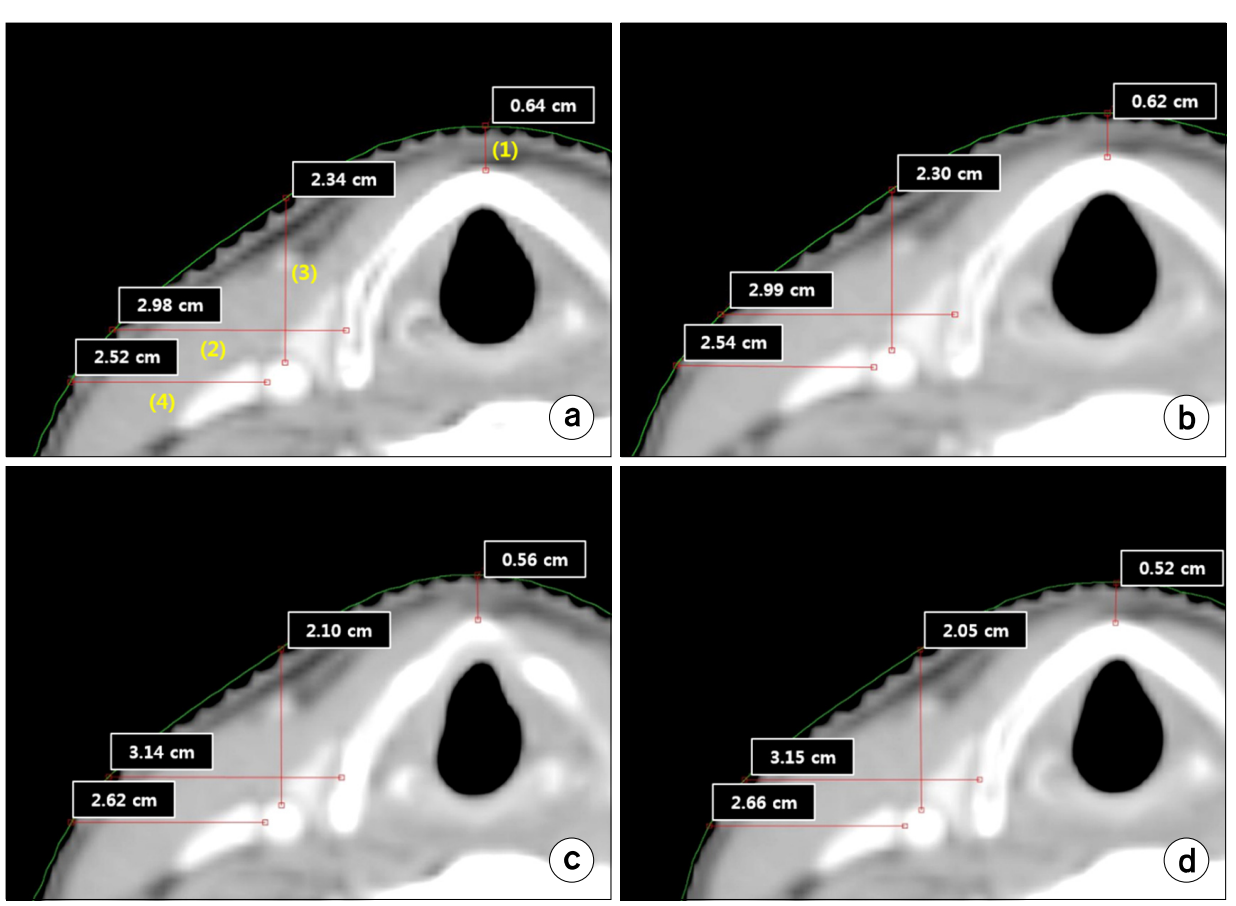

Fig. 2. Measurement and comparison of the distances between skin surface and each 4 points (OARs) in a typical patient. The change of body type occurs owing to the changing weight according to the progress of treatment. (a) planningkVCT, (b) 1week, (c) 3week, (d) 5 week. (1) The distance between the anterior surface of thyroid cartilage and the skin. (2) The distance between the lateral surface of thyroid cartilage and the skin. (3) The distance between the anterior surface of carotid artery and the skin. (4) The distance between the lateral surface of carotid artery and the skin.
피부 사이의 거리는 평균 $0.7 \pm 0.2 \mathrm{~mm}$ 으로 줄었고, 측면표 면과 피부 사이의 거리는 평균 $0.9 \pm 1.0 \mathrm{~mm}$ 으로 증가하였 다. 경동맥의 앞쪽표면과 피부 간의 거리는 평균 $2.1 \pm 0.4 \mathrm{~mm}$ 으로 감소하였고, 측면표면과 피부 간의 거리는 평균 $0.6 \pm$ $0.7 \mathrm{~mm}$ 증가하였다. Barkar, ${ }^{11)}$ Schwartzem ${ }^{12)}$ 그리고, $\mathrm{Lu} \mathrm{W}^{13,14)}$ 등은 두경부암에서 방사선치료 과정 중 체중의 변화에 의 해 OARs의 체적이 변하였으며 체표 윤곽의 변화로 인해 해부학적인 이동이 발생하여 결과적으로 치료 계획된 선량 과 실제 전달되는 선량이 차이가 날 수 있다고 보고 한 바 있다. 그러나, 본 연구에서 치료 기간 중에 체중변화는 3 주 후부터 뚜렷한 변화가 있었으며, 성문, 경동맥 그리고, 갑 상선 샘은 해부학적 특성상 체중변화에 따른 체적의 변화 가 민감하게 반응하지 않았다. 그럼에도 불구하고, 실제적
으로 체적의 변화는 크지 않았지만 체중변화로 인하여 체 표 윤곽의 변화가 발생된 피부와 OARs 사이의 거리변화는 두경부암에서 구조물의 변화가 발생되었다는 점을 의미할 수 있다.

\section{3. 종양에 대한 선량평가분석인자}

Table 2에서는 치료 기간에 따른 PTV에 대한 선량 평가 인자들을 보여주고 있다. $\mathrm{PITV}, \mathrm{TCI}, \mathrm{rDHI}, \mathrm{mDHI}$ 그리고, $\mathrm{CN}$ 은 치료 계획된 값보다 각각 평균 $4.32 \pm 1.97 \%, 5.78 \pm$ $3.35 \%, 44.54 \pm 14.15 \%, 12.32 \pm 6.80 \%$ 그리고, $7.11 \pm 4.65 \%$ 으로 감소하였다. 또한, $\mathrm{PTV}$ 의 $\mathrm{D}_{\max }, \mathrm{D}_{\text {mean }}, \mathrm{V}_{67.50}$ 그리고, $\mathrm{D}_{95}$ 는 각각 평균 $2.99 \pm 1.87 \%, 1.52 \pm 0.61 \%, 5.78 \pm 3.35 \%$ 그리고, $11.94 \pm 6.79 \%$ 로 증가 또는 감소하였다. PTV체적의 변화는 
Table 2. Dose evaluation of PTV during the course of treatment.

\begin{tabular}{lcccccc}
\hline \hline Factor & Planning-kVCT & 1 week & 2 week & 3 week & 4 week & 5 week \\
\hline $\mathrm{D}_{\text {max }}$ & $76.49 \pm 3.22$ & $79.61 \pm 6.51$ & $77.41 \pm 3.56$ & $79.27 \pm 8.72$ & $77.26 \pm 4.05$ & $80.64 \pm 6.33$ \\
$\mathrm{D}_{\text {mean }}$ & $71.55 \pm 1.73$ & $70.93 \pm 1.34$ & $70.36 \pm 1.42$ & $70.87 \pm 1.35$ & $70.02 \pm 1.45$ & $70.03 \pm 1.43$ \\
$\mathrm{~V}_{67.50}(\%)$ & $95.00 \pm 0.00$ & $93.35 \pm 2.24$ & $92.78 \pm 4.45$ & $88.94 \pm 4.03$ & $88.27 \pm 3.82$ & $85.19 \pm 5.70$ \\
$\mathrm{D}_{95}(\mathrm{~Gy})$ & $67.50 \pm 0.00$ & $64.55 \pm 6.04$ & $63.88 \pm 6.49$ & $54.73 \pm 18.36$ & $55.57 \pm 13.74$ & $58.48 \pm 9.91$ \\
PITV & $0.99 \pm 0.01$ & $0.97 \pm 0.03$ & $0.96 \pm 0.04$ & $0.94 \pm 0.04$ & $0.93 \pm 0.05$ & $0.92 \pm 0.05$ \\
TCI & $0.95 \pm 0.00$ & $0.93 \pm 0.02$ & $0.92 \pm 0.04$ & $0.89 \pm 0.04$ & $0.88 \pm 0.04$ & $0.85 \pm 0.06$ \\
rDHI & $0.67 \pm 0.13$ & $0.49 \pm 0.24$ & $0.52 \pm 0.27$ & $0.33 \pm 0.26$ & $0.336 \pm 0.26$ & $0.31 \pm 0.18$ \\
mDHI & $0.91 \pm 0.03$ & $0.87 \pm 0.10$ & $0.86 \pm 0.11$ & $0.74 \pm 0.26$ & $0.75 \pm 0.20$ & $0.78 \pm 0.15$ \\
CN & $0.91 \pm 0.01$ & $0.90 \pm 0.02$ & $0.88 \pm 0.05$ & $0.84 \pm 0.07$ & $0.84 \pm 0.04$ & $0.79 \pm 0.10$ \\
\hline \hline
\end{tabular}

Note: $\mathrm{V}_{67.50}=$ the volume included in $67.50 \mathrm{~Gy}, \mathrm{D}_{95}=$ the dose included in $95 \%$ volume. PITV=PIV/PTV (PIV is the prescription isodose volume coverage for the target and normal tissues. PITV $>1$ and PITV $<1$ refers to the over treatment and under treatment regions, repectively.), TCI=PTV $\mathrm{pd} / \mathrm{PTV}\left(\mathrm{PTV}_{\mathrm{pd}}\right.$ is the PTV coverage at PD, and PTV has usual meaning), $\mathrm{rDHI}=\mathrm{D}_{\min } / \mathrm{D}_{\max }, \mathrm{mDHI}=\mathrm{D}_{95} / \mathrm{D}_{5}$, $\mathrm{CN}=\mathrm{TCI} / \mathrm{TR}$ ( $\mathrm{CN}$ accounts for the relative measurement of dosimetric target coverage and sparing of normal tissues in a treatment plan).

Table 3. Dose evaluation of carotid artery.

\begin{tabular}{lllll}
\hline \hline \multicolumn{1}{c}{ Weekly } & $\mathrm{V}_{40}(\mathrm{cc})$ & $\mathrm{V}_{50}(\mathrm{cc})$ & $\mathrm{D}_{\max }(\mathrm{Gy})$ & $\mathrm{D}_{\text {mean }}(\mathrm{Gy})$ \\
\hline Planning-kVCT & $20.19 \pm 9.62$ & $11.39 \pm 8.23$ & $72.79 \pm 8.41$ & $17.90 \pm 6.5$ \\
1 week & $20.42 \pm 8.29$ & $11.27 \pm 7.91$ & $73.87 \pm 5.17$ & $17.95 \pm 6.38$ \\
2 week & $20.22 \pm 9.49$ & $11.55 \pm 7.34$ & $73.62 \pm 8.48$ & $17.73 \pm 6.52$ \\
3 week & $21.20 \pm 9.27$ & $12.04 \pm 8.58$ & $74.03 \pm 5.46$ & $17.87 \pm 6.90$ \\
4 week & $21.12 \pm 11.31$ & $11.98 \pm 8.88$ & $74.85 \pm 5.51$ & $18.66 \pm 7.36$ \\
5 week & $21.88 \pm 10.16$ & $12.39 \pm 10.58$ & $74.32 \pm 4.55$ & $18.31 \pm 7.58$ \\
Average & $20.84 \pm 9.70$ & $11.77 \pm 8.59$ & $73.91 \pm 6.26$ & $18.07 \pm 6.87$ \\
\hline \hline
\end{tabular}

Note: $\mathrm{V}_{40}=$ the volume (cc) of $40 \mathrm{~Gy}, \mathrm{~V}_{50}=$ the volume of $50 \mathrm{~Gy}$.

체중과 연관성이 높지는 않았지만, 치료가 진행됨에 따라 선량 평가인자들이 최초 치료 계획보다 점점 감소하는 추 세를 보였다. 1보다 작은 값을 가진 PITV는 치료가 충분히 되지 않은 체적이 있다는 것을 의미한다. 본 연구에서 PITV는 치료가 경과 됨에 따라 지수함수적으로 감소 하였 고 이는 치료 기간에 PTV에 대한 선량포함이 치료 기간에 따라 감소된다는 것을 의미한다. 특히 $\mathrm{TCI}$ 와 $\mathrm{V}_{67.50}$ 의 결과 값은 처방선량에 포함되는 체적이 3 주 후부터 평균적으로 $6 \%$ 감소 되었고, 치료 종료에는 $10 \%$ 감소하였다. IMRT는 종래치료(conventional therapy) 방법이었던 2D나 3D에 비해 PTV에 같은 처방선량을 전달하면서 PTV의 여유마진을 최 소로 하여 정상조직을 최대한 보호하는 고정밀 치료기술이 다. 고정밀 치료기술의 장점은 환자에서 체적변화나 체형 변화가 나타나 해부학적인 오차가 발생하였을 경우 $2 \mathrm{D}$ 나 $3 \mathrm{D}$ 치료법에 비해 PTV에서 선량포함의 감소가 더 커질 수 있다고 보고되고 있다. ${ }^{15,16)}$ 본 연구에서 PTV의 선량포함의
감소폭이 커지기 시작하는 기간은 체중의 변화폭이 커지는 시점과 일치함으로 이러한 결과는 체형의 변화가 원인이 된다고 사료된다.

\section{4. 정상조직에 대한 선량평가분석인자}

Table 3에서 경동맥에 대한 선량 평가를 기술하였고 이 것은 35 50 Gy 이상에서 내막-중막 두께(intimal-medial thickness, IMT)가 증가한다는 Martin 등 ${ }^{17}$ 의 보고를 참고하 여 $\mathrm{V}_{40}, \mathrm{~V}_{50}, \mathrm{D}_{\max }, \mathrm{D}_{\text {mean }}$ 에 대해 비교하였다. 경동맥의 $\mathrm{V}_{40}$ 과 $\mathrm{V}_{50}$ 은 치료 계획상의 값과 비교하였을 때 2주 동안은 각 $-1.06 \% \sim 1.40 \%$ 의 증가 혹은 감소를 보였지만 $3 \sim 5$ 주 동 안은 $4.59 \% \sim 12.09 \%$ 로 증가 하였다. $\mathrm{D}_{\max }, \mathrm{D}_{\operatorname{mean}}$ 는 치료 기 간 동안 평균적으로 각 $1.35 \pm 0.47 \mathrm{~Gy}, 0.20 \pm 0.38 \mathrm{~Gy}$ 가 증가 하였다. 갑상선 샘은 $30 \mathrm{~Gy}$ 이상 전달받은 체적이 갑상선 기능저하증(hypothyroidism)의 위험을 평가할 수 있다는 Akgun 등 ${ }^{18}$ 의 보고를 참조하여 Table 4 에 $\mathrm{V}_{30}, \mathrm{~V}_{40}, \mathrm{D}_{\max }$, 
Woo Chul Kim, et al : Evaluation of Dose Change by Using the DIR on the IMRT with Glotiis Cancer

Table 4. Dose evaluation of thyroid gland.

\begin{tabular}{lcccc}
\hline \hline Weekly & $\mathrm{V}_{30}(\mathrm{cc})$ & $\mathrm{V}_{40}(\mathrm{cc})$ & $\mathrm{D}_{\max }(\mathrm{Gy})$ & $\mathrm{D}_{\text {mean }}(\mathrm{Gy})$ \\
\hline Planning-kVCT & $28.44 \pm 22.39$ & $25.15 \pm 21.30$ & $75.57 \pm 2.60$ & $20.77 \pm 14.86$ \\
1 week & $27.35 \pm 19.17$ & $24.22 \pm 17.71$ & $75.35 \pm 2.56$ & $18.53 \pm 12.70$ \\
2 week & $27.34 \pm 20.59$ & $23.25 \pm 18.02$ & $74.98 \pm 2.78$ & $19.29 \pm 12.68$ \\
3 week & $24.17 \pm 18.34$ & $21.33 \pm 17.16$ & $74.98 \pm 2.59$ & $17.76 \pm 11.90$ \\
4 week & $24.23 \pm 21.80$ & $20.92 \pm 20.45$ & $74.97 \pm 2.72$ & $17.70 \pm 14.31$ \\
5 week & $20.96 \pm 15.60$ & $17.92 \pm 13.54$ & $74.59 \pm 2.86$ & $15.45 \pm 9.59$ \\
Average & $25.42 \pm 19.65$ & $22.13 \pm 18.03$ & $74.85 \pm 2.67$ & $18.25 \pm 12.67$ \\
\hline \hline
\end{tabular}

Note: $\mathrm{V}_{30}=$ the volume of $30 \mathrm{~Gy}, \mathrm{~V}_{40}=$ the volume of $40 \mathrm{~Gy}$.
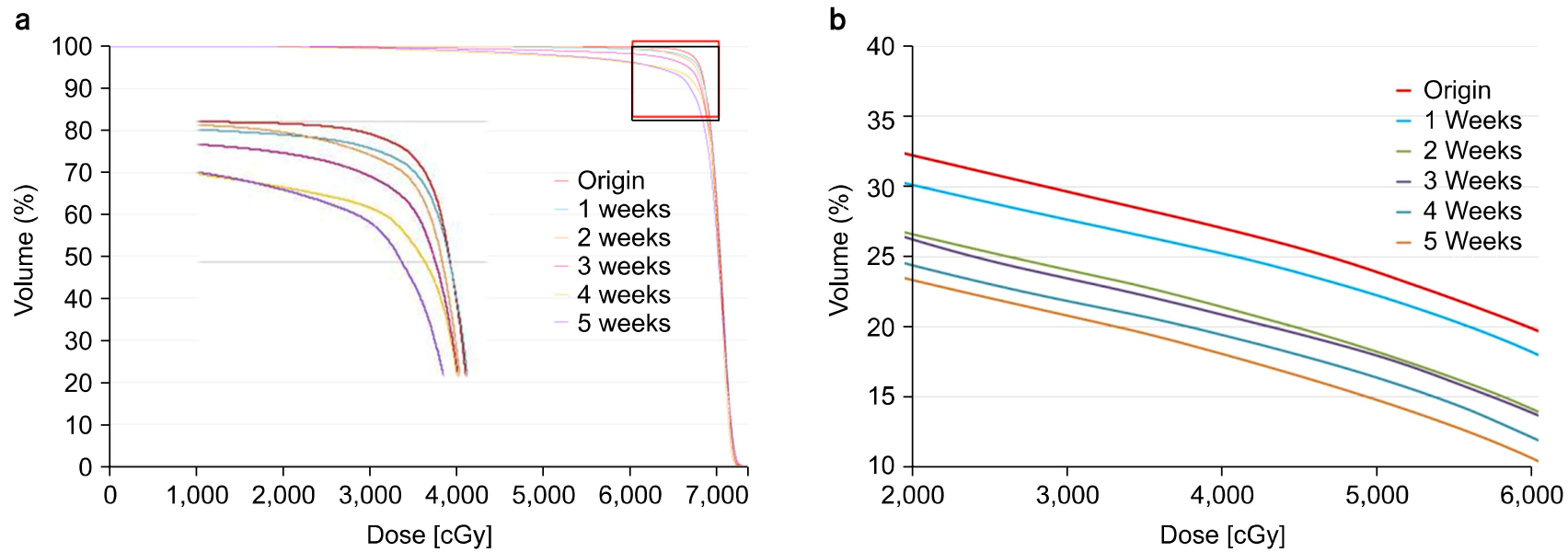

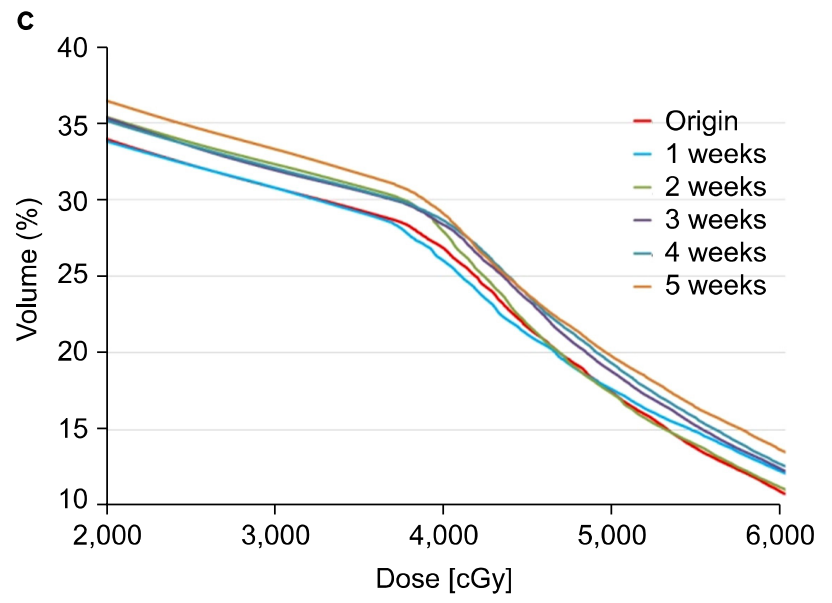

$\mathrm{D}_{\text {mean }}$ 를 비교 하였다. $\mathrm{V}_{30}, \mathrm{~V}_{40}$ 의 값은 치료 계획상의 값과 비교 하였을 때 평균적으로 2주 동안 $-3.57 \%$ 2.63\%의 변 화를 보였고 $3 \sim 5$ 주 동안은 $12.05 \% \sim 26.4 \%$ 가 감소하였다. $\mathrm{D}_{\max }, \mathrm{D}_{\text {mean }}$ 는 치료 기간 동안 평균적으로 각 $0.58 \pm 0.27 \mathrm{~Gy}$, $3.02 \pm 1.44 \mathrm{~Gy}$ 가 감소하였다. 경동맥과 갑상선의 선량 평가 에 대한 결과는 PTV와 마찬가지로 3주 후부터 변화폭이 커지는 것을 알 수 있었다.
Fig. 3. Comparison of dose volume histogram (DVHs) for different plans (original Vs. recalculation) from experimental data in a typical patient. (a) PTV, (b) thyroid gland, (c) carotid artery.

성문암의 방사선 치료에서 IMRT는 긴 치료 시간으로 환 자의 연동운동에 따라 정밀도가 감소하고 이차종양의 발생 위험성 등과 의료진의 업무량 증가, 환자 비용 증가 등을 고려한다면 대항 2 문 조사에 비해 이득이 크지 않다는 보 고가 있다. ${ }^{16)}$ 그러나 두경부암의 방사선 치료에서 경동맥 에 35 50 Gy 이상 조사된 경우 경동맥의 내막-중막 두께 가 두꺼워지고 치료 후 협착증을 유발하여 뇌졸증을 발생 
시키는 원인이 된다고 보고되고 있다. ${ }^{19)}$ Rosenthal DI. 등 ${ }^{1)}$ 의 연구에 따르면 성문암의 방사선 치료 시 대항 2 문 조사 는 경동맥에 조사되는 방사선양이 $\mathrm{D}_{40}, \mathrm{D}_{50}$ 모두 $60 \mathrm{~Gy}$ 이 상 전달되었지만 IMRT 에서는 D40, D50 에서 15 25 Gy 이내로 줄일 수 있어 성문암의 방사선 치료 시 IMRT 의 필요성을 보고하였다. 최근 보고된 $\mathrm{Kim}$ 등 $^{20}$ 의 연구에 의 하면 갑상선 샘의 $\mathrm{V}_{45}$ 는 hypothyroidism을 유발시킬 수 있는 임계치라고 나와 있다. 갑상선 샘은 성문의 인접장기로 대 항 2 문 조사로 전달되는 선량을 줄이기에는 한계가 있기 때문에 IMRT 치료가 필요하다.

초기 병기의 성문암의 경우 예방적 경부 임파절 조사를 하지 않기 때문에, 보통 PTV 조절에 의한 중간치료계획변 경을 하지 않는다. 경동맥과 갑상선 샘의 부작용을 고려하 지 않은 대항 2 문 조사 치료에서는 비교적 넓은 여유마진 을 가지고 치료를 하였기 때문에 PTV에 대한 선량포함의 변화는 적었을 것이라 사료된다. 반면 IMRT 에서는 PTV에 서 최소한의 여유마진을 가지고 치료 계획을 하기 때문에 체중 변화에 따른 체형 변화나 환자 자세에 따른 오차 등 에 PTV는 민감하다. Nishi $\mathrm{T}^{\text {등 }}{ }^{21}$ 의 연구에서는 두경부암 의 IMRT 치료 시 3 4 주에 37\% 81\%의 체적 변화와 이 하선이 $4.2 \mathrm{~mm}$ 이동하는 체형 변화가 발생하였고 이에 따 른 선량학적인 변화는 두 번째 치료 계획이 필요하다고 보 고하였다. Figure 3은 특정 환자의 DVH를 나타낸 것으로 치료 경과에 따른 PTV, 경동맥 및 갑상선샘을 비교하였으 며 같은 시기에 변화폭이 커지는 걸 확인할 수 있었다. 본 연구의 결과에 따르면 체중의 변화가 발생되는 3 주 후부터 종양에 대한 치료 성적이 크게 감소하기 시작하였고 경동 맥에 대한 피폭선량은 증가하였다. 또한 갑상선 샘의 전달 선량도 3 주 후부터 변화가 컸으나 감소되는 현상을 보인 것은 PTV에 가깝게 인접해 있기 때문에 PTV의 치료 성적 이 감소하면서 같이 감소된 것으로 예상된다. 이 결과는 치 료가 경과된 3주 후부터는 종양에 대한 치료효과는 감소하 고 경동맥에 대한 부작용이 증가하였다는 것을 의미하며, 치료 기간 중 체중의 변화에 따른 PTV의 체적변화는 없더 라도 체형의 변화를 관찰하여 맞춤형 치료계획(adaptive plan) 과정을 고려해야 한다고 사료된다.

\section{결 론}

방사선 치료에서 치료기술의 발달은 환자에게 최소한의 부작용과 종양 부위에 최대한의 선량을 전달하여 정확한 치료를 할 수 있다. 그러나 IMRT와 부피적세기조절회전치 료(volumetric modulated arc therapy, VMAT) 등과 같은 고정 밀 치료기술은 많은 장점을 가지고 있음에도 불구하고 환 자의 체중변화에 의하여 치료계획보다 PTV의 선량포함이 감소되고 결정장기에 전달되는 선량의 차이로 인해 부작용 을 발생시킬 수 있다. 또한, 두경부암의 방사선치료는 종양 과 결정장기들은 피부와 인접하여 위치하기 때문에 체중의 변화로 인한 결정장기들의 체적과 체형변화에 선량 분포가 민감하게 작용할 수 있다. 본 연구에서 체중의 변화에 따른 체형의 변화는 해부학적 구조물들의 체적 변화와 무관하게 PTV 및 결정장기에 선량 분포의 변화를 가져왔다. 3 주가 지난 시점에서 변화폭이 커짐을 확인하였고, 재치료계획이 필요하다는 결과를 얻었다. 본 연구의 결과를 통해 성문암 뿐만 아니라 두경부암의 고정밀 치료기술을 적용한 방사선 치료 시 환자의 체중변화에 대해 지속적인 관찰이 필요하 다. 치료 중 변형영상정합기법을 이용하여 선량분포를 평 가하는 것은 중요하며 선량분포의 변화가 발생되었다면 맞 춤형 치료계획을 통해 정확한 선량전달이 필요하다고 사료 된다.

\section{References}

1. Rosenthal DI, Fuller CD, Barker JL Jr, Mason B, Garcia JA, Lewin JS: Simple carotid-sparing intensity-modulated radiotherapy technique and preliminary experience for T1-2 glottic cancer. Int J Radiat Oncol Biol Phys 77(2):455-461 (2010)

2. Geets X, Tomsej M, Lee JA, et al: Adaptive biological imageguided IMRT with anatomic and functional imaging in pharyngolaryngeal tumors: Impact on target volume delineation and dose distribution using helical tomotherapy. Radiother Oncol 85:105-115 (2007)

3. Wu Q, Chi Y, Chen PY, et al: Adaptive replanning strategies accounting for shrinkage in head and neck IMRT. Int $J$ Radiat Oncol Biol Phys 75:924-932 (2009)

4. Hunter KU, Fernandes LL, Vineberg KA, et al: Parotid glands dose-effect relationships based on their actually delivered doses: implications for adaptive replanning in radiation therapy of head-and-neck cancer. Int J Radiat Oncol Biol Phys 87(4):676-682 (2013)

5. Nishimura $Y$, Nakamatsu K, Shibata $T$, et al: Importance of the initial volume of parotid glands in xerostomia for patients with head and neck cancers treated with IMRT. Jpn J Clin Oncol 35:375-379 (2005)

6. Schwartz DL, Garden AS, Thomas J, et al: Adaptive radiotherapy for head-and-neck cancer: Initial clinical outcomes from a prospective trial, Int. J. Radiat. Oncol. Biol. Phys 83:986993 (2011)

7. Mencarelli A, van Beek S, van Kranen S, Rasch C, van Herk M, Sonke JJ: Validation of deformable registration in 
Woo Chul Kim, et al : Evaluation of Dose Change by Using the DIR on the IMRT with Glotiis Cancer

head and neck cancer using analysis of variance. Med Phys 39(11):6879-6884 (2012)

8. Yan D, Liang J: Expected treatment dose construction and adaptive inverse planning optimization: implementation for offline head and neck cancer adaptive radiotherapy. Med Phys 40(2): 021719 (2013)

9. Mike O, Jeff C, Eugene W, Jake VD, Francisco P: A treatment planning study comparing whole breast radiation therapy against conformal, IMRT and tomotherapy for accelerated partial breast Irradiation. Radiother Oncol 82:317-323 (2007)

10. Bhide SA, Davies M, Burke K, et al: Weekly volume and dosimetric changes during chemoradiotherapy with intensitymoudulated radiation therapy for head and neck cancer: a prospective observational study. Int. J. Radiat. Oncol. Biol. Phys 76:1360-1368 (2010)

11. Barker JL, Gargen AS, Ang KK, et al: Quantification of volumetric and geometric changes occurring during fractionated radiotherapy for head-and-neck cancer using an integrated CT/linear accelerator system, Int. J. Radiat. Oncol. Biol. Phys 59:960-970 (2004)

12. Schwartz DL, Garden AS, Thomas J, et al: Adaptive radiotherapy for head-and-neck cancer: Initial clinical outcomes from a prospective trial, Int. J. Radiat. Oncol. Biol. Phys 83:986993 (2011)

13. Lu W, Chen ML, Olivera GH, et al: Fast free-form deformable registration via calculus of variation. Phys. Med. Biol 49: 3067-3087 (2004)

14. Lu W, Olivera GH, Chen $\mathrm{Q}$, et al: Deformable registration of the planning image(KVCT) and the daily images(MVCT) for adaptive radiation therapy. Phys. Med. biol 51:4357-4374 (2006)

15. Ahn PH, Chen CC, Ahn Al, et al: Adaptive planning intensity-modulated radiation therapy for head and neck cancers: single-institution experience and clinical implications. Int. J. Radiat. Oncol. Biol. Phys. 3:677-685 (2011)

16. Feigenberg SJ, Lango M, Nicolaou N, Ridge JA: Intensitymodulated radiotherapy for early larynx cancer: is there a role? Int J Radiat Oncol Biol Phys 1;68(1):2-3 (2007)

17. Martin JD, Buckley AR, Graeb D, Walman B, Salvian A, Hay JH: Carotid artery stenosis in asymptomatic patients who have received unilateral head-and-neck irradiation. Int $J$ Radiat Oncol Biol Phys 63:1197-1205 (2005)

18. Akgun Z, Atasoy BM, Ozen Z, et al: V30 as a predictor for radiation-induced hypothyroidism: a dosimetric analysis in patients who received radiotherapy to the neck. Radiation Oncology 9:104:1-5 (2014)

19. Cheng SW, Ting AC, Ho P, Wu LL: Accelerated progression of carotid stenosis in patients with previous external neck irradiation. J Vasc Surg 39:409-415 (2004)

20. Kim MY, Yu TS, Wu HG: Dose-volumetric Parameters for Predicting Hypothyroidism after Radiotherapy for Head and Neck Cancer. Jpn J Clin Oncol 44:331-337 (2014)

21. Nishi T, Nishimura $Y$, Shibata T, Tamura M, Nishigaito $\mathrm{N}$, Okumura $\mathrm{M}$ : Volume and dosimetric changes and initial clinical experience of a two-step adaptive intensity modulated radiation therapy (IMRT) scheme for head and neck cancer. Radiother Oncol 106(1):85-89 (2013) 


\title{
성문암 세기조절 방사선치료에서 변형영상정합을 이용한 선량변화 평가
}

\author{
*순천향대학교 의과대학 방사선종양학교실, ${ }^{\dagger}$ 경기대학교 의학물리학과, \\ ${ }^{\dagger}$ 고려대학교 의과대학 방사선종양학교실, ${ }^{{ }^{8}}$ 원자력의학원 방사선치료연구부, \\ "가톨릭대학교 의과대학 의공학교실, 생체의공학연구소, "경기대학교 일반대학원 전자물리학과

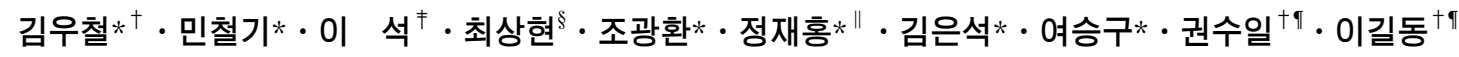 \\ 본 연구는 IMRT가 적용된 성문암 환자에 대하여 $\mathrm{CBCT}$ 영상과 변형영상 정합기법을 이용하여 치료기간 동안 실제 환자 \\ 에게 전달되는 선량 변화를 평가하고자 하였다. B-spline 알고리즘을 사용한 변형영상정합 시스템을 통해 치료 중 1주 \\ 간격으로 얻은 $\mathrm{CBCT}$ 를 재구성하고 치료계획을 재계산하여 종양과 결정장기의 선량 분포를 비교하였다. 체중에 따른 체 \\ 적변화는 3 5 주부터 평균 1.38 2.04 kg로 증가하였으며 체표면의 변화는 평균 $2.1 \mathrm{~mm}$ 로 감소하였다. 또한, 3주 이후 \\ 의 경동맥에 전달된 선량은 계획되었던 값보다 최대 $8.76 \%$ 로 증가하였고, 갑상선샘은 $26.4 \%$ 로 감소하였다. 종양의 물리 \\ 적의 평가인자인 PITV, TCl, rDHI, $\mathrm{mDH}$ 그리고, $\mathrm{CN}$ 은 치료 계획된 값보다 각각 평균 $4.32 \%, 5.78 \%, 44.54 \%, 12.32 \%$ 그리 \\ 고, $7.11 \%$ 로 감소하였다. PTV에 대한 $\mathrm{D}_{\max }$ 는 평균 $2.99 \%$ 증가하였고, $\mathrm{D}_{\operatorname{mean}}, \mathrm{V}_{67.50}$, $\mathrm{D}_{95}$ 는 각각 평균 $1.52 \%, 5.78 \%, 11.94 \%$ \\ 로 감소하였다. 체중변화에 따른 체적의 변화가 없더라도 체형변화는 발생하였고, 좁은 여유마진을 가지는 IMRT는 이러 \\ 한 변화에 민감하게 반응하였다. 성문암에 대한 IMRT 적용 시 환자의 체중변화를 관찰과 함께 변화를 기록하고 치료 중 \\ 변형영상정합 시스템을 이용하여 선량분포를 평가할 필요가 있다. 최종적으로 치료 중 실제 전달되는 선량평가는 적응 \\ 형치료계획을 통하여 확인하고 정확한 선량전달이 필요하다고 사료된다.
}

중심단어: 성문암, 변형영상정합, $\mathrm{CBCT}, \mathrm{ART}$ 